\title{
AS TAFROGÊNESES SUPERPOSTAS ESPINHAÇO E SANTO ONOFRE, ESTADO DA BAHIA: REVISÃO E NOVAS PROPOSTAS
}

\author{
CARLOS SCHOBBENHAUS*
}

\begin{abstract}
THE SUPERIMPOSED ESPINHAÇO AND SANTO ONOFRE TAPHROGENIES, STATE OF BAHIA: REVISION AND NEW PROPOSALS The built up of the Espinhaço rift in the states of Bahia and Minas Gerais, took place along NS and NW-SE faults. In the State of Bahia the initial phase of the taphrogeny was marked by the Rio dos Remédios volcanism, dated at about $1750 \mathrm{Ma}(\mathrm{U}-\mathrm{Pb})$, and followed by the deposition of more than 5,000 meters of continental and shallow marine sediments. These units represent the Espinhaço supergroup in the northern part of the Espinhaço range and in the Chapada Diamantina plateau. A second extensional phase at the beginning of the Neoproterozoic, between 1000 and $900 \mathrm{Ma}$, lead to a new rifting episode in the area of the Espinhaco supergroup and its basement. Old faults of the former aborted Espinhaço rift were reactivated. A triple junction was developed in the southeastern margin of the São Francisco craton. In the lesser active arm of this junction the Santo Onofre rift was formed, penetrating the site of the Espinhaço supergroup in the State of Bahia. Along this neoproterozoic rift continental and marine sediments including turbiditic lobes were deposited. These units are represented by the redefined Santo Onofre group, which outcrops along the strike of the Espinhaco supergroup. The southern extension of the redefined Santo Onofre group is represented by the Macaubas group, in the upper Pardo river, northern Minas Gerais. Both southernly located limbs of the triple junction are represented by the assimetric Macaubas rift, which opens to the east to form a passive continental margin - the Araçuaf basin. In the Chapada Diamantina plateau, a discordance at the basis of the Morro do Chapéu formation, is interpreted to be genetically related to the deposition of the redefined Santo Onofre group. The Morro do Chapéu formation represents therefore also a neoproterozoic unit. On the other hand, the Tombador and Caboclo formations are mesoproterozoic platform sediments $(\sim 1200-1000 \mathrm{Ma})$, probably related to a geodynamic event of grenvillian age. The closing of the Macaubas basin during the Brasiliano orogenesis, lead to the formation of the Araçuai belt and to the deformation of the Santo Onofre group along the so called Paramirim deformation corridor in the interior of the São Francisco craton. This deformation involved also the Espinhaço system and its basement.
\end{abstract}

Keywords: Proterozoic, rift, stratigraphy, paleogeography

RESUMO A estruturação do rift Espinhaço nos estados da Bahia e Minas Gerais está ligada a fase extensional no final do Paleoproterozóico (1800-1700 Ma) e ocorreu ao longo de falhas NS e NW-SE. Na Bahia, a fase inicial dessa tafrogênese é marcada pelo vulcanismo Rio dos Remédios, datado em $1750 \mathrm{Ma}(\mathrm{U}-\mathrm{Pb})$, seguida da deposição de mais de 5000 metros de sedimentos continentais e marinhos rasos, que no seu conjunto compõem o Supergrupo Espinhaço, ao longo da Serra do Espinhaço setentrional e Chapada Diamantina. Uma fase extensional no início do Neoproterozóico, entre 1000 e 900 Ma, gera um novo episódio de tafrogênese. Antigas linhas de falha do rift Espinhaço abortado são reativadas. Na borda sudeste do atual cráton do São Francisco forma-se uma junção tríplice. Ao longo do braço menos ativo dessa junção gera-se o rift Santo Onofre que penetra o sítio do Espinhaço baiano, possivelmente por reativação da falha de Santo Onofre, com mais de $500 \mathrm{~km}$ de extensão. Ao longo desse rift depositam-se sedimentos continentais e marinhos (incluindo lobos turbidíticos) neoproterozóicos, representados pelo Grupo Santo Onofre redefinido, aflorando ao longo do strike do Supergrupo Espinhaço. A extensão meridional do Grupo Santo Onofre redefinido é representado pelo Grupo Macaúbas, na bacia do alto Rio Pardo, norte de Minas Gerais. Os dois ramos meridionais dessa junção tríplice representam o rift assimétrico Macaúbas que, para leste, abre-se na bacia oceânica Araçuaí. Na Chapada Diamantina, a discordância da base da Formação Morro do Chapéu, definida como importante limite de seqüência, é geneticamente relacionada à deposição de unidades do Grupo Santo Onofre redefinido. Essa formação representa, portanto, também uma unidade neoproterozóica. Por outro lado, as formações Tombador e Caboclo, representam sedimentos plataformais mesoproterozóicos ( 1200-1000 Ma), provavelmente relacionados a um evento geodinâmico de idade grenvilliana. O fechamento da bacia Macaúbas durante a orogênese brasiliana, resultou na formação da faixa Araçuaí e na deformação do Grupo Santo Onofre redefinido ao longo do chamado corredor de deformação do Paramirim, no interior do cráton do São Francisco. Essa deformação envolveu também o sistema Espinhaço e seu embasamento.

Palavras-chave: Proterozóico, rift, estratigrafia, paleogeografia

INTRODUÇÃO O desenvolvimento das primeiras estruturas tafrogênicas no início do Proterozóico (Hoffman 1973) e a sua ampla ocorrência no final do Paleoproterozóico e durante o Mesoproterozóico são indicativas de uma progressiva cratonização dos continentes, pois requerem a existência de plataformas estáveis. O aparecimento das Proterozoic-like rocks, na denominação de Windley (1984), representa um novo estágio na história da Terra: crátons maiores se estabilizaram, permitindo a deposição de espessas seqüências supracrustais, sucedendo o regime permobile do Arqueano. As litofácies do Paleoproterozóico (2500-1600 Ma) e Mesoproterozóico (1600-1000 Ma) mostram alta proporção de areias quartzosas. Sobre os crátons arqueanos estabilizados, contendo greenstone-belts e intrusões de plutões ácidos, se estabeleceram bacias com deposição de conglomerados com seixos de quartzo e espessas seqüências de arenitos quartzíticos (Hoppe 1988, Goodwin 1991).
O cenário acima descrito ajusta-se ao Supergrupo Espinhaço, inclusive pela presença de um novo tipo de sedimento que apareceu no limiar Paleo/Mesoproterozóico e que implica na presença de uma atmosfera oxidante: os red-beds. Da mesma forma como na África, onde foram primeiramente gerados entre 1800 e $1700 \mathrm{Ma}$, os mais antigos red-beds também ocorrem no Brasil (Pedreira \& Margalho 1990).

O Supergrupo Espinhaço ocorre ao longo da serra homônima, com mais de $1000 \mathrm{~km}$ de extensão e largura média de $20 \mathrm{~km}$. Distribui-se com direção meridiana desde o Quadrilátero Ferrífero, Minas Gerais, cortando toda a Bahia até os limites do Piauí e Pernambuco. Representa um conjunto de unidades continentais e marinhas de origem tafrogênica, maiormente psamíticas, em parte pelíticas, carbonáticas e vulcânicas, cuja deposição inicial transcorreu entre 1750 e $1700 \mathrm{Ma}$. Essa idade insere-se no período Estateriano (1800$1600 \mathrm{Ma}$ ), final do Paleoproterozóico (Fuck 1991). O nome 
dado à esse período faz alusão à uma fase mundial de cratonização ou estabilização de plataformas.

$\mathrm{Na}$ Bahia, esse supergrupo foi interpretado como um rift intracratônico (Jardim de Sá 1981) ou um aulacógeno (Costa $\&$ Inda 1982) e, em Minas Gerais, como um rift passando a uma margem continental passiva ( Almeida-Abreu \& Pflug 1994, Almeida-Abreu 1995 ) que em fase posterior experimentou evento orogenético no ciclo Espinhaço, bem como reativação no ciclo Brasiliano. Já, Uhlein (1991), Trompette et al. (1992), Schobbenhaus (1993), Alkmim et al (1993), Dussin \& Dussin (1995), Rocha \& Dominguez (1993) e outros interpretam o Supergrupo Espinhaço como um rift abortado que sofreu deformação e metamorfismo somente na orogênese brasiliana.

A correlação entre as unidades do Supergrupo Espinhaço, na Serra do Espinhaço meridional e setentrional e na Chapada Diamantina, tem sido aceita genericamente a nível regional, por diversos autores, sem maiores restrições nos últimos 20 anos, com base em semelhanças litofaciológicas e tectônicas gerais (Pflug et al 1969, Brito Neves et al 1979, Schobbenhaus et al 1981, Uhlein 1991, entre outros), apesar de que os limites cronoestratigráficos desse supergrupo não estivessem bem definidos ainda e, muito menos, a sua evolução paleogeográfica e tectono-estrutural.

Alguns autores associam o nome Espinhaço, como já referido, a um ciclo geodinâmico cuja deposição, deformação e metamorfismo teria ocorrido entre o final do ciclo Transamazônico e o início do ciclo Brasiliano. O chamado evento tectono-metamórfico Espinhaço representaria dessa maneira o auge de deformação e metamorfismo desse ciclo, que teria ocorrido ou entre 1300 e 1000 Ma (Jardim de Sá 1981, Inda \& Barbosa 1978, Brito Neves et al 1980), ou em $1400 \mathrm{Ma}$ (Turpin et al. 1988) ou ainda em $1500 \mathrm{Ma}$ (Cordani et al 1992, Almeida-Abreu 1995), gerando o sistema de dobramentos ou a faixa dobrada Espinhaço.

No momento atual, a existência ou não de um evento tectono-metamórfico Espinhaço, é assunto controverso. $\mathrm{O}$ ponto central da polêmica reside na dificuldade de se caracterizar de forma inequívoca um evento tectono-metamórfico nas unidades do Supergrupo Espinhaço, anteriormente ao evento Brasiliano. As deformações que afetaram as unidades espinhaçoanas são também encontradas em unidades do ciclo Brasiliano (Uhlein et al 1986, Uhlein \& Pedreira 1989, Danderfer 1990, Uhlein 1991). Por outro lado, o registro de uma orogênese espinhaçoana nos sistemas radiométricos é indefinida.

Novos dados aqui expostos vem corroborar a tese de deformação e metamorfismo únicos para a Serra do Espinhaço,ocorridos no evento brasiliano. Uma integração de dados regionais realizados pelo autor, na Bahia e norte de Minas Gerais, possibilita apresentar uma nova proposta interpretativa para a evolução geodinâmica da Serra do Espinhaço setentrional e Chapada Diamantina (Schobbenhaus 1993). Trata-se da existência de um rift neoproterozóico (Santo Onofre) superposto ao rift Espinhaço, na Serra do Espinhaço setentrional (Figura 1).

O SUPERGRUPO ESPINHAÇO NA BAHIA Na Bahia, esse supergrupo está exposto em ambos os lados do vale do Rio Paramirim, maiormente sobreposto ao complexo Paramirim, de idade arqueana (Figura 1). Do lado oeste desse complexo, o Supergrupo Espinhaço tem sido representado em trabalhos anteriores pelo Grupo Santo Onofre (Porcher 1970, Schobbenhaus 1972a) edificando a Serra do Espinhaço setentrional e, do lado leste, pelos grupos Rio dos Remédios (Schobbenhaus \& Kaul 1971), Paraguaçu (Derby 1906, Mascarenhas et al 1979) e Chapada Diamantina (Leal \& Brito Neves 1968) que sustentam a unidade morfológica da Chapada Diamantina (Figura 1). Dominguez (1996) reúne os grupos Rio dos Remédios e Paraguaçu em uma única seqüência deposicional, enquanto o Grupo Chapada Diamantina é dividido por esse autor em duas seqüências distintas: Tombador-Caboclo (Derby 1906, Branner 1910) e Morro do Chapéu (Brito Neves 1967) que representam as formações desse grupo, da base para o topo, respectivamente.

Uma modificação no conceito dado ao Grupo Santo Onofre é proposta. Este seria representado, tanto por unidades do Supergrupo Espinhaço, quanto por unidades correlatas ao Grupo Macaúbas (Schobbenhaus 1993). Para as primeiras, é proposta a denominação de Grupo Oliveira dos Brejinhos e para as segundas sugere-se manter o nome Grupo Santo Onofre. Como já referido, essa interpretação propõe a existência de uma sedimentação neoproterozóica ao longo da faixa dobrada da Serra do Espinhaço, abrindo perspectivas para uma nova interpretação geotectônica dessa área. Essa unidade neoproterozóica é representada pelo Grupo Santo Onofre redefinido, estando superposta a unidades do Supergrupo Espinhaço. De fato, existe uma continuidade estrutural e uma identidade de litofácies entre o Grupo Santo Onofre redefinido e o Grupo Macaúbas. As litofácies psamito-pelíticas e as pelito-grafitosas do Grupo Santo Onofre redefinido (Grupo Espinhaço Superior de Costa et al 1975) podem ser seguidas continuamente com estruturação de direção meridiana, ao longo da Serra do Espinhaço, no sentido sul, até se confundirem com unidades do Grupo Macaúbas, na região do alto Rio Pardo, norte de Minas Gerais (Schobbenhaus 1972b,c, Costa et al 1975, Viveiros et al 1978, Noce et al 1993, PedrosaSoares 1996).

O Grupo Oliveira dos Brejinhos A estratigrafia desse grupo proposto por Schobbenhaus (1993), baseia-se em Schobbenhaus (1972a) e Costa \& Silva (1980). Com espessura estimada em 3.000 metros, esse grupo é representado, da base para o topo, pelas formações Pajeú (Kaul 1970; arcóseos, conglomerados, vulcanites), Bom Retiro (Porcher 1970; quartzitos, conglomerados), Fazendinha (Costa \& Silva 1980; quartzitos, xistos) e Serrada Vereda (Kaul 1970; dumortierita e/ou cianita-quartzitos) (Figuras 2 e 3 ). Na região de Oliveira dos Brejinhos, área-tipo desse grupo, a Formação Pajeú inicia por conglomerado polimicto depositado em profunda discordância sobre o complexo Paramirim. As vulcânicas Pajeú tem caráter predominantemente intermediário a ácido, com tendência alcalina a subalcalina (Jardim de Sá 1978, Fernandes et al 1982). Idades K-Ar, entre $580 \mathrm{Ma}$ e $520 \mathrm{Ma}$, obtidas dessas vulcânicas, mostram a atuação do evento Brasiliano na área (Távora et al 1967). Uma correlação entre as vulcânicas da Formação Pajeú e do Grupo Rio dos Remédios é admissível. As vulcânicas Pajeú, no entanto, carecem de datações geocronológicas mais precisas. À oeste, os dumortierita e/ou cianita quartzitos da Formação Serra da Vereda são considerados como unidade de contato com o Grupo Santo Onofre redefinido. Trata-se supostamente de uma inconformidade paralela ou uma paraconformidade (Bates \& Jackson 1987), cuja natureza demanda estudos mais detalhados.

A bacia de sedimentação do Grupo Oliveira dos Brejinhos é interpretada como um rift de orientação meridiana que, na sua fase inicial, esteve condicionado a um vulcanismo félsico, em ambiente continental, associado a sistemas fluviais, de leques aluviais e eólicos. Em direção ao topo, a bacia grada para sistemas flúvio-deltáico a marinho de águas rasas (Inda \& Barbosa 1978, Costa \& Silva 1980, Dominguez 1996).

É provável que a falha de Santo Onofre (Figs. 2 e 3) e outras falhas tenham agido, já no final do Paleoproterozóico, como falhamentos normais no desenvolvimento do rift e tenham sido reativadas no Neoproterozóico, durante a sedimentação do Grupo Santo Onofre redefinido. A falha de Santo Onofre, de direção $\mathrm{N} 15^{\circ} \mathrm{W}$, representa uma feição tectônica maior, com extensão superior a $500 \mathrm{~km}$, reconhecida desde o paralelo 


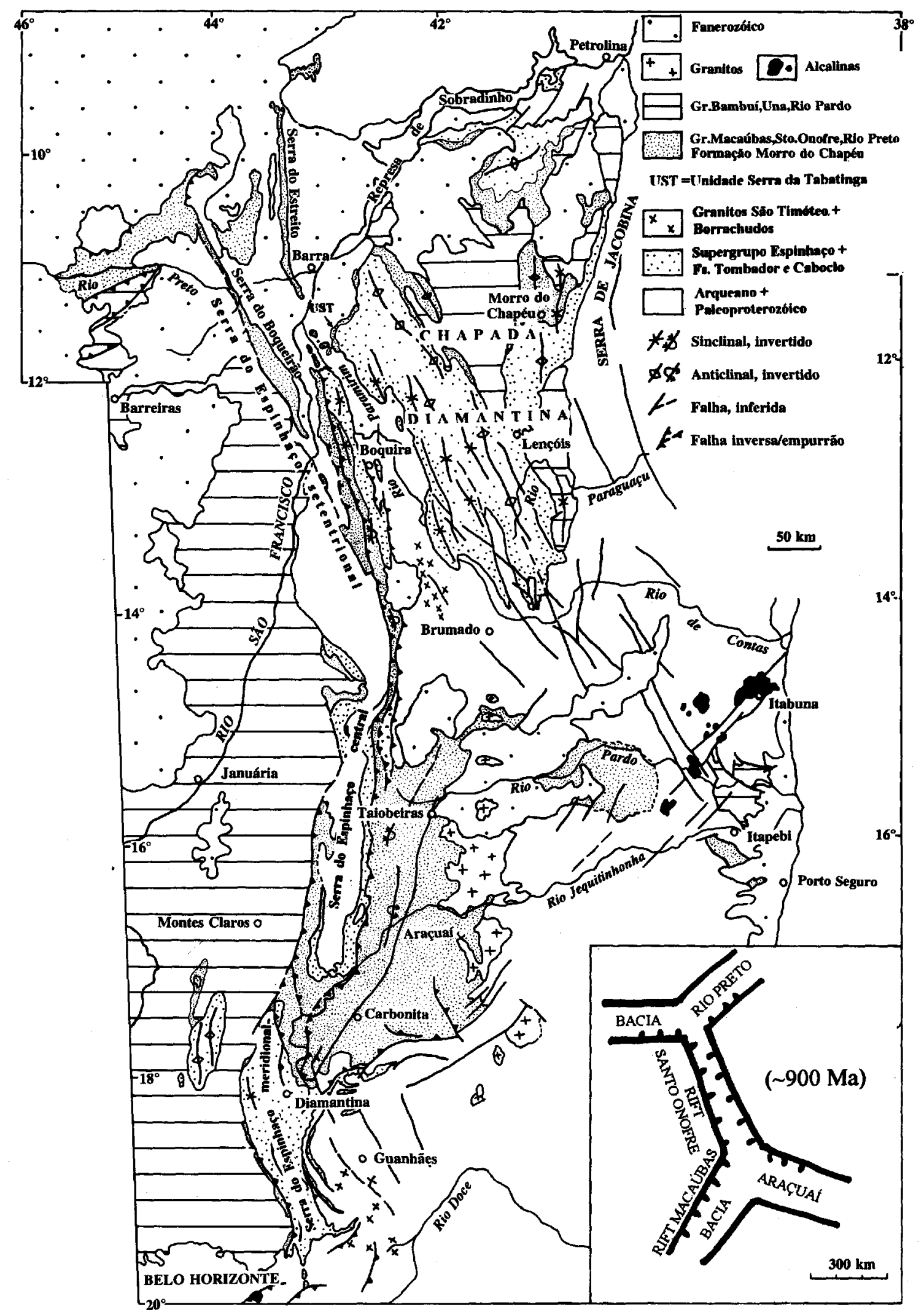

Figura 1 - Mapa geológico da Serra do Espinhaço e Chapada Diamantina, nos estados da Bahia e Minas Gerais. Modificado de Schobbenhaus et al. (1981).

Figura 1 - Geologic map of the Espinhaço range and Chapada Diamantina plateau in the states of Bahia and Minas Gerais. Modified from Schobbenhaus et al. (1981). 
$12^{\circ}$ até, pelo menos, o paralelo $17^{\circ}$, em Minas Gerais. Uma nova reativação dessa falha deve ter ocorrido durante a deformação de todo o conjunto no evento Brasiliano.

Por outro lado, o Grupo Oliveira dos Brejinhos é tipicamente cortado por diques e sills básicos que podem ser acompanhados, normalmente com direção meridiana, por dezenas de quilômetros, em toda extensão dessa unidade. No Grupo Santo Onofre redefinido, ou seja a oeste da serra da Vereda, essas rochas básicas estão totalmente ausentes (Costa \& Silva 1980) (Figura 2). Esse fato, levou Costa et al (1975) e Inda \& Barbosa (1978) a dividirem o Supergrupo Espinhaço, nessa área, em duas unidades distintas: uma mais antiga cortada por rochas básicas (Grupo Espinhaço Médio) e uma mais jovem isenta dessas rochas (Grupo Espinhaço Superior). A presença de rochas básicas cortando o Supergrupo Espinhaço é uma característica típica dessas unidades, tanto na Serra do Espinhaço na Bahia, quanto em Minas Gerais.

O Grupo Santo Onofre redefinido O Grupo Santo Onofre redefinido por Schobbenhaus (1993), acha-se tipicamente exposto ao longo do Rio Santo Onofre (Figuras 2 e 3 ). Esse grupo é formado por espessas seqüências de quartzitos, quartzitos com intercalações de filitos, filitos com intercalações de quartzitos e raras lentes de calcários. Os filitos têm proporções variadas de hematita, grafita e mais raramente óxidos de manganês. $\mathrm{O}$ teor de carbono fixo nos filitos grafitosos pode chegar a $12 \%$. Nos filitos ocorrem também níveis ricos de cloritóide e/ou pirita. Uma unidade quartzítica de topo, com intercalações de filitos ${ }_{\gamma}$ transgride a oeste sobre rochas do embasamento arqueano. A leste, uma seqüência de quartzitos, xistos e filitos, com a presença constante de biotita, está em contato brusco com a unidade de topo do Grupo Oliveira dos Brejinhos.

O Grupo Santo Onofre redefinido corresponde às formações Santo Onofre e Sítio Novo de Inda \& Barbosa (1978) e Dominguez (1996). A sul, prossegue em faixa contínua para Minas Gerais. É provável que o Grupo Santo Onofre também esteja incorporado aos metassedimentos que edificam as serras do Boqueirão e Estreito, no extremo norte da Serra do Espinhaço (Winge 1968, Silva et al. 1989), juntamente com o Grupo Oliveira dos Brejinhos. Estudos específicos nas serras do Boqueirão e Estreito poderão esclarecer esses aspectos. As serras do Boqueirão e do Estreito são limitadas a norte pela faixa dobrada Rio Preto, gerada no Neoproterozóico. O Grupo Santo Onofre redefinido é provavelmente correlacionável ao Grupo Rio Preto, incorporado à faixa homônima (Inda \& Barbosa 1978, Silva et al 1989).

As relações de contato do Grupo Santo Onofre redefinido com o embasamento arqueano, à oeste, são relativamente mal expostas. Aí, as unidades Santo Onofre mostram-se pouco deformadas e a oeste do Rio São Francisco, já no domínio plataformal, são cobertas por calcários do Grupo Bambuí. O Rio Santo Onofre, ao longo do qual transcorre a falha homônima, coincide com as maiores espessuras desse grupo, estimadas em alguns milhares de metros. A falha de Santo Onofre representou provavelmente importante eixo da bacia de sedimentação brasiliana na Serrado Espinhaço setentrional e central. A dinâmica dessa falha ao longo da história geológica dessa área é pouco conhecida, assim como a litoestratigrafia e sistemas deposicionais do Grupo Santo Onofre redefinido. De maneira geral, as fácies são areno-pelíticas finamente laminadas associadas a pelitos grafitosos amplamente distribuídos, com pirita e, às vezes, com óxidos de manganês e ferro, sugerindo ambiente marinho restrito de águas calmas ou um grande lago de circulação restrita, em ambiente redutor. A laminação rítmica associada à possível presença de seqüências de Bouma sugere fácies distais de depósitos turbidíticos, formados em águas marinhas mais profundas por deslizamento subaquoso de massas de sedimen- tos. O aprofundamento da bacia para o topo foi acompanhado de uma transgressão sobre o continente no sentido oeste (Schobbenhaus 1972a, Jardim de Sá 1978, Costa \& Silva 1980, Fernandes et al 1982). Quartzitos intercalados em filitos do topo do Grupo Santo Onofre redefinido são interpretados por Dominguez et al (1996) como depositados por correntes de turbidez de alta densidade. À oeste do Rio São Francisco, próximo a Ibotirama, Uhlein \& Pedreira (1989) descrevem arenitos e siltitos com fácies de planície de maré e barras de off-shore, em ambiente plataformal, correlacionados a esse grupo.

Em áreas isoladas, ao longo do contato com o embasamento arqueano, à oeste, ocorrem brechas epiclásticas e tectônicas que passam lateralmente a arcóseos. Essa unidade, denominada de João Dias por Costa \& Silva (1980), representa a base do Grupo Santo Onofre (Figuras 2 e 3). A matriz é de cor esverdeada e constitui uma grauvaca microconglomerática. A sua origem é provavelmente mista. Uma parte é epiclástica (fanglomerática), evidenciando certo transporte e soterramento rápido. Uma outra parte é interpretada como de origem cataclástica, formada pela brechação de blocos falhados (Costa \& Silva 1980).

A deformação que afetou os grupos Oliveira dos Brejinhos e Santo Onofre redefinido foi gerada por um único esforço compressional (Costa \& Silva 1980, Uhlein \& Pedreira 1989).

\section{O SISTEMA ARAÇUAÍ-PARAMIRIM-RIO PRETO}

Essa denominação reúne três unidades tectono-estruturais distintas, mas geneticamente relacionadas: a faixa Araçuaí (Almeida 1977, Almeida et al 1978, Pedrosa-Soares et al 1992, Siga Jr. 1986, Uhlein et al 1990), a província Paramirim (Trompette et al 1992) ou corredor de deformação do Paramirim (Alkmim et al 1993) e a faixa Rio Preto (Inda \& Barbosa 1978, Silva et al 1989).

A faixa Araçuaí, cuja parte mais externa define o limite da borda sudeste do cráton do São Francisco (sensu Almeida 1977), foi traçada tentativamente por Almeida et al (1978) ao longo de áreas supostamente influenciadas pelo ciclo Brasiliano. A deformação do Supergrupo Espinhaço no norte de Minas Gerais e B ahia era creditada a uma deformação pré-brasiliana (ciclo Espinhaço ou Uruaçuano). Atualmente, demonstra-se a influência da deformação do ciclo Brasiliano no interior do cráton do São Francisco, ao longo do Serra do Espinhaço setentrional (Caby \& Arthaud 1987, Turpin et al. 1988, Danderfer 1990; Uhlein 1991, Bertholdo et al 1993). Tratado como assunto controvertido há duas décadas, novas informações disponíveis levaram Trompette et al (1992) a formalizar proposta de dividir essa área cratônica em duas unidades, separadas pela província ou faixa Paramirim, como já sugerido por Cordani (1973): à oeste, o cráton do São Francisco sensu stricto e, à leste, o cráton Salvador, uma extensão ocidental do cráton Congo (Figura 4). A faixa Paramirim ou corredor do Paramirim foi deformada e retrabalhada no ciclo Brasiliano, pelo fechamento do rift Santo Onofre (Schobbenhaus 1993) afetando toda a Serra do Espinhaço setentrional e a borda oeste da Chapada Diamantina (Figura 1). No entanto, a polêmica em torno da subdivisão do cráton do São Francisco, ainda persiste. Em contraposição ao modelo de Trompette et ai (1992), Alkmim et al (1993) propõem que a deformação brasiliana no corredor do Paramirim foi induzida por mecanismo focado em faixas marginais, não justificando a subdivisão do cráton sensu Almeida (1977). De fato, não existem evidências suficientes para admitir um limite de placa ou uma zona de sutura no corredor do Paramirim. À luz do conhecimento atual, o rift Santo Onofre pode ser entendido como uma zona de acomodação (accomodation zone) ou um braço intracratônico, exclusivamente ensiálico, durante a fase de geração dos rifts e o posterior desenvolvimento das bacias marginais Araçuaí e Rio Preto. 


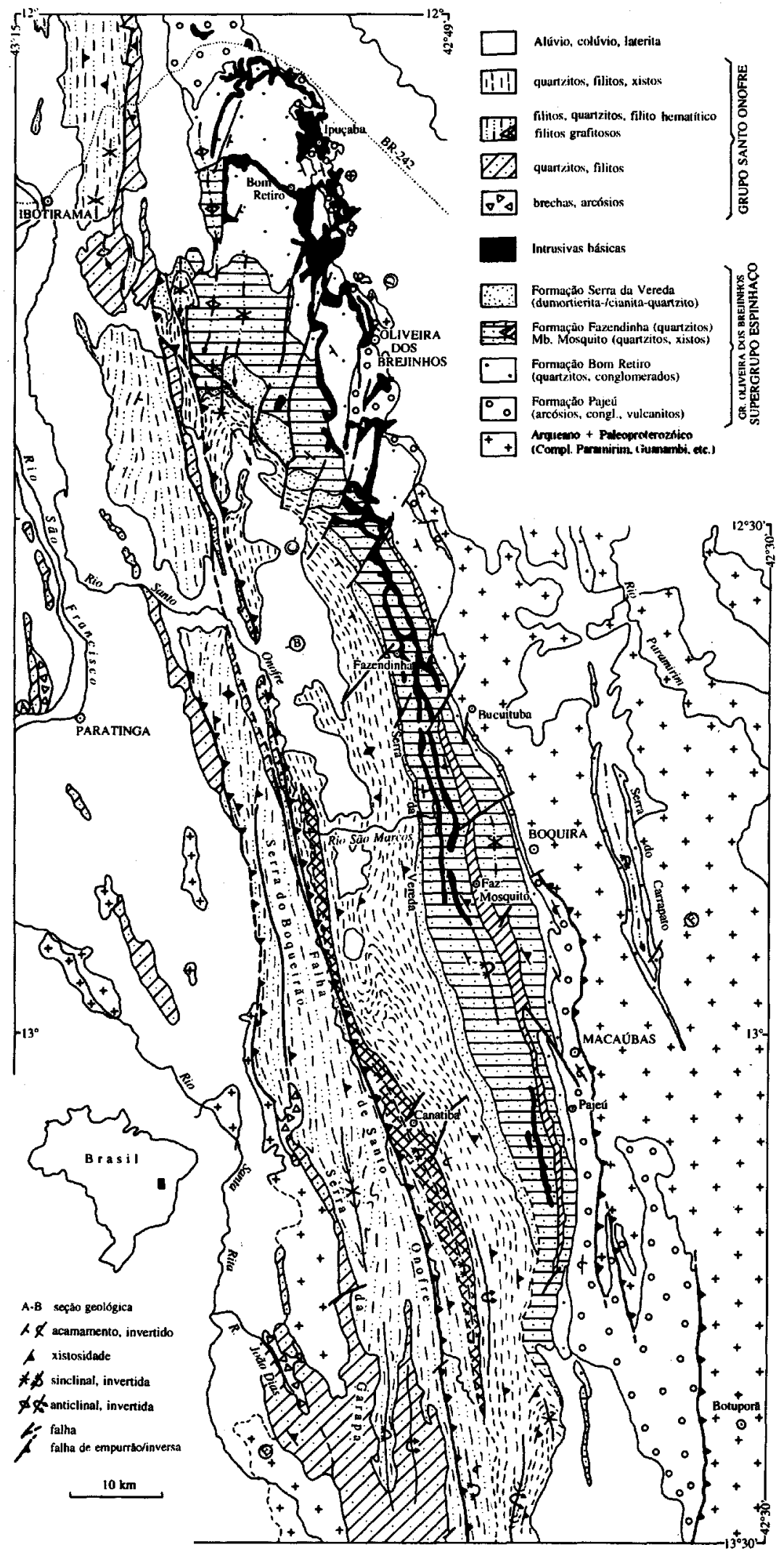

Figura 2 - Mapa geológico de parte da Serra do Espinhaço setentrional, Bahia. Modificado de Schobbenhaus (1972a) e Costa \& Silva (1 980). Seções geológicas AB, CD e EF: vide Figura 3.

Figure 2 - Geologic map of part of the northern Espinhaço range, Bahia. Modified from Schobbenhaus (1972a) and Costa \& Silva (1980). Geologic sections AB, CD e EF: see Figura 3. 

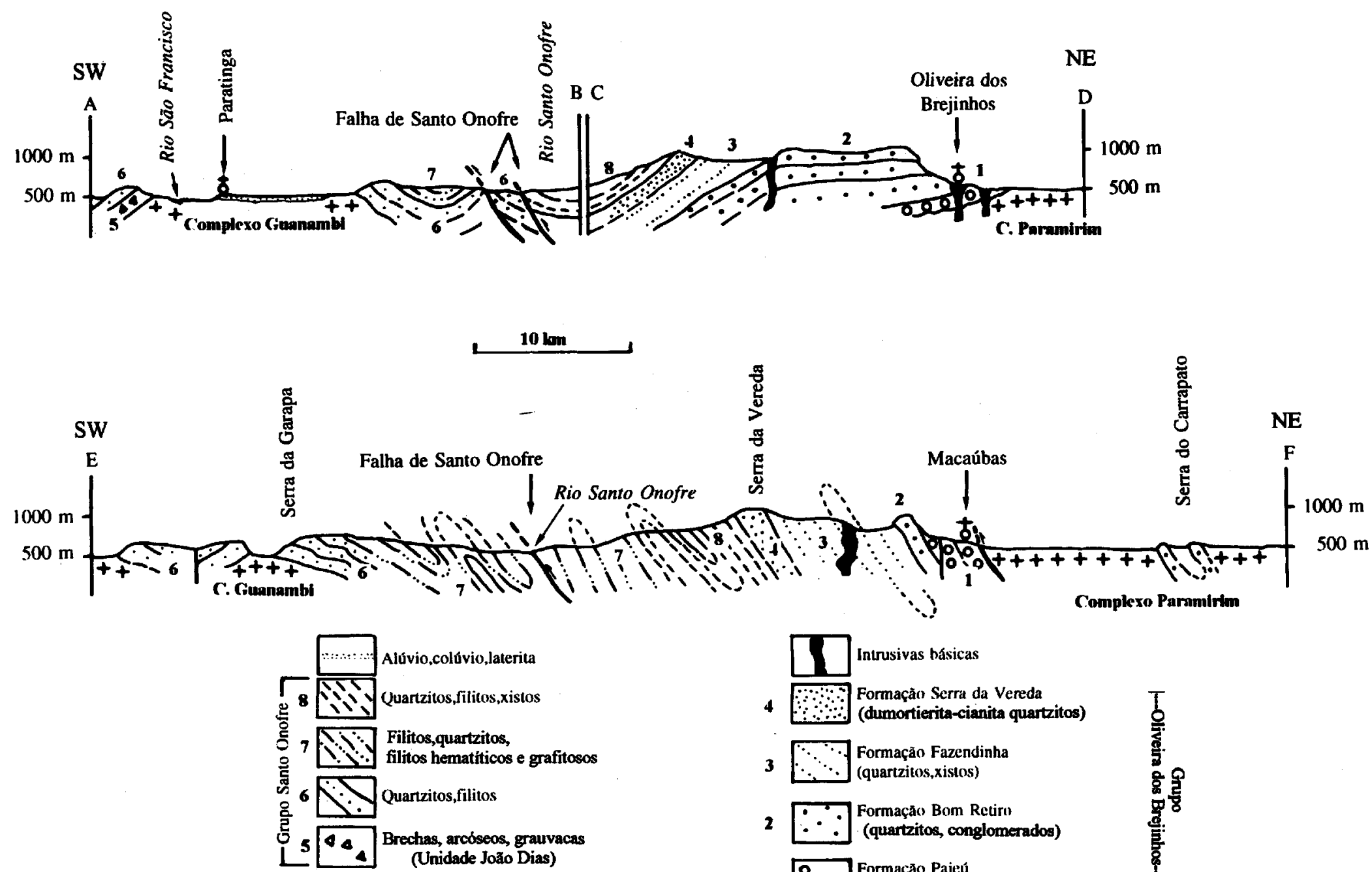

\section{$\square$ Intrusivas básicas}

4 Formaçăo Serra da Vereda

$3 \quad \because$ Formação Fazendinha

$\because \ddots$ (quartzitos,xistos)

$2\left[\because \begin{array}{l}\text { Formaçăo Bom Retiro } \\ \text { (quartzitos, conglomerados) }\end{array}\right.$

$1{ }^{\circ}$ o $\begin{gathered}\text { Formaçāo Pajeú } \\ \text { (arcóseos }\end{gathered}$

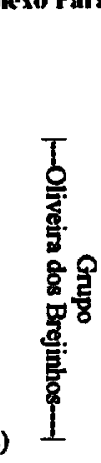

++ Arqueuno + Paleoproterozólco 
EVOLUCÃO GEODINÂMICA O rift Espinhaço (1750 Ma) A tafrogênese responsável pela deposição do Supergrupo Espinhaço, na Bahia, implantou-se preferencialmente sobre uma infraestrutura de rochas essencialmente arqueanas (complexo Paramirim) que foram afetadas pela orogênese Transamazônica. $\mathrm{O}$ regime tectônico que presidiu o desenvolvimento da tafrogênese Espinhaço, foi desencadeada em seguida à epirogênese do final daquele ciclo tectônico, em torno de $1800 \mathrm{Ma}$ (Brito Neves et al. 1980, Teixeira 1982). O estágio extensional levou a um rifting crustal, possivelmente ao longo de antigas linhas de fraqueza e que possibilitou a estruturação de áreas-fonte e áreas subsidentes condicionadoras da sedimentação Espinhaço.

A estruturação geral do rift Espinhaço ocorreu ao longo de falhas de orientação NS a NW-SE com esforços de distensão E-W. Isso é sugerido por extensas falhas que percorrem esse supergrupo e pelo posicionamento de áreas-fonte que alimentaram o rift.

A fase inicial do rift é marcada por um vulcanismo essencialmente félsico subalcalino, associado a uma sedimentação detrítica continental. De modo mais restrito, esse vulcanismo teve também caráter bimodal e pode mostrar afinidade alcalina.

O Grupo Rio dos Remédios na borda ocidental da Chapada Diamantina, na Bahia, representa amplamente esse magmatismo inicial. Essa unidade, definida inicialmente por Schobbenhaus \& Kaul (1971), constitui um conjunto de rochas vulcânicas ácidas a intermediárias, com associação subordinada de rochas sedimentares elásticas e piroclásticas, depositadas em ambiente continental (Jardim de Sá 1978, McReath et al. 1981; Souza 1986; Pedreira 1988). O padrão geoquímico apresentado pelos elementos traços assemelha-se ao de rochas ácidas continentais de afinidade toleiítica, principalmente aquelas de origem atribuída à anatexia de rochas crustais, em regiões anorogênicas, a grandes profundidades da crosta. $\mathrm{O}$ caráter químico do vulcanismo é interpretado como de natureza subalcalina com ligeira afinidade potássica (Conceição 1974, Jardim de Sá 1978, Fernandes et al 1982). Na base da Serra do Espinhaço setentrional, algumas dezenas de $\mathrm{km}$ à oeste, esse vulcanismo ocorre na Formação Pajeú, evidenciando um caráter alcalino. Análises de zircão pelo método $\mathrm{U} / \mathrm{Pb}$ da região de Paramirim forneceram discórdias de 1752 Ma (Schobbenhaus et al 1994) e 1748 Ma (Babinski et al. 1994). Esses valores permitem realizar uma correlação cronológica desse vulcanismo com as vulcânicas félsicas da Serra do Espinhaço meridional, datadas entre 1770e $1700 \mathrm{Ma}$ (Brito Neves et al 1979, Machado et al. 1989, Dussin et al 1995) e com as vulcânicas félsicas da base do Grupo Araí, em Goiás, datadas em $1770 \mathrm{Ma}$ (Pimentel et al 1991). Esse último fato indica um desenvolvimento também lateral do rift Espinhaço, para oeste (rift Araí). Durante o vulcanismo inicial do rift Espinhaço houve também a geração de granitos, cuja intrusão ocorreu no embasamento pré-Espinhaço, na região de Paramirim-Caetité-Lagoa Real, sul da Bahia. Esses granitos são referidos como São Timóteo (Jardim de Sá 1978) ou complexo granítico de Lagoa Real (Caby \& Arthaud 1987). Na região de Lagoa Real esses granitos, em parte, são representados por ortognaisses associados à mineralização de urânio. $\mathrm{O}$ protólito desses granitos foi datado pelo método $\mathrm{U}-\mathrm{Pb}$ em $1746 \mathrm{Ma}$ (Pimentel et al 1993) e sua intrusão provavelmente ocorreu em ambiente extensional. O granito São Timóteo pode ser correlacionado cronologicamente ao granito Borrachudos, à leste da Serra do Espinhaço meridional, datado em 1729 Ma (Dussin \& Dussin 1995).

Uma correlação entre os sistemas deposicionais ao longo da Serra do Espinhaço e na Chapada Diamantina indica, para a fase inicial do Supergrupo Espinhaço, um cenário de bacia de sedimentação terrígena continental, tectonicamente ativa, com vulcanismo subaéreo associado. Para o topo há interdigi- tação com um sistema deposicional desértico, que lateralmente e para cima, mostra interação com litofácies de sistemas lacustres, deltáicos ou marinhos rasos. Esse sistema deposicional corresponde, na Serra do Espinhaço setentrional, ao Grupo Oliveira dos Brejinhos e na Chapada Diamantina aos grupos Rio dos Remédios e Paraguaçu, esse último com espessura superior a 3000 metros.

A fase inicial ou sinrift do Espinhaço é marcada por rápidas e freqüentes variações faciológicas e sedimentação controlada por sistemas ativos de horst e graben (Uhlein 1991). Passa progressivamente para uma bacia de maior estabilidade e alargamento do sítio deposicional.

Uma fase de relativa quiescência tectônica da bacia Espinhaço pode ter sido precedida por um estágio de sagging (Hoffman 1973), devido à contração do manto por dissipação do calor, indicando um período de subsidência térmica e flexural pós-rift (Uhlein 1991). Discordâncias locais observáveis nas unidades basais do Supergrupo Espinhaço podem relacionar-se ao basculamento de blocos (block tilting) e flexuras desse estágio de contração.

\section{A seqüência deposicional Tombador-Caboclo ( 1200-1000 Ma) A polaridade sedimentar dessa} seqüência deposicional (Dominguez 1993), em especial da Formação Tombador (Otero et al 1989) indica a existência de uma importante área-fonte (cordilheira Jacobina-Contendas-Mirante), situada à leste da Chapada Diamantina (Montes 1977, Montes et al 1981, Pedreira \& Margalho 1990) (Figura 4). Na Formação Tombador há importantes níveis congíomeráticos, comumente diamantíferos. Na serra do Sincorá (sudeste da Chapada Diamantina), em especial, essa formação foi depositada pela atuação de sistemas de leques aluviais, fluvial e flúvio-eólico (Bonfim \& Pedreira 1990). A Formação Caboclo documenta a invasão e o posterior recuo de um mar raso sujeito a tempestades sobre unidades continentais Tombador (Silveira 1991, Guimarães \& Pedreira 1990). Além de sedimentos siliciclásticos tipicamente plataformais, a Formação Caboclo apresenta importantes ocorrências de rochas carbonáticas, representadas principalmente por construções estromatolíticas (Silveira 1991, Dominguez \& Rocha 1991, Monteiro et al 1984). A assembléia de estromatólitos observada na Formação Caboclo sugere posicioná-la no Rifeano Médio (1350-950 Ma) (Rocha et al 1990). Amostras desses calcários estromatolíticos datados por Babinski et al (1993) pelo método isocrônico $\mathrm{Pb}-\mathrm{Pb}$, definiram idade de $1140 \pm 140$ Ma. Dentro do erro analítico, esses últimos autores consideram essa idade como mínima de sedimentação, representando a época de anquimetamorfismo que afetou a Formação Caboclo. Datações Rb-Sr de illitas contidas em argilitos e siltitos da Formação Caboclo, indicam idade de $960 \mathrm{Ma}$ para sua diagênese tardia (Macedo \& Bonhomme 1984).

Na Chapada Diamantina a deposição das formações Tombador e Caboclo, com cerca de 500 metros de espessura, transgride para norte e leste sobre o embasamento pré-Espinhaço. A extensão e regularidade dessas unidades reflete a estabilidade tectônica da bacia.

O caráter transgressivo dessas unidades, a discordância erosiva na base da Formação Tombador, a inversão da polaridade sedimentar em relação ao Grupo Paraguaçu, bem como os dados geocronológicos e paleobiológicos disponíveis, são indicativos de que as formações Tombador e Caboclo representam unidades sem relação com o desenvolvimento do Supergrupo Espinhaço. Provavelmente, representam sedimentos plataformais mesoproterozóicos geneticamente relacionados a um evento tectônico mais jovem, de idade grenvilliana. O Cariris Velhos recentemente estudado no Nordeste pode representar esse evento (Brito Neves et al 1996).

A ocorrência de uma atividade vulcânica ácida no Grupo Chapada Diamantina é representada sob a forma de diques 
cortando as formações Tombador e Caboclo ou como finas camadas de tufos intercalados (Montes 1977; Fernandes et al. 1982, Pedreira \& Margalho 1990). Não há datações disponíveis para essas vulcânicas.

Fase extensional ( $1000-900$ Ma) Importante episódio de rifting desenvolveu-se no sítio de Espinhaço entre 1000 e $900 \mathrm{Ma}$. O arqueamento crustal provavelmente associado à essa fase extensional levou ao levantamento e erosão parcial da cadeia Espinhaço. O nível de exumação em algumas áreas alcançou as suas unidades basais ou mesmo provocou a sua erosão total.

Essa tectônica epirogenética é acompanhada da intrusão de abundantes rochas básicas no Supergrupo Espinhaço (Figuras 2 e 3) e em seu embasamento, por meio de fraturas de tensão que reativaram antigas linhas de fraqueza, de direção generalizada N-S. Esse magmatismo, datado entre 1000 e 900 Ma, tem características geoquímicas continentais e antecede a deposição das unidades Santo Onofre, Morro do Chapéu e Macaúbas. Diques básicos dessa natureza e idade também foram detectados fora da área em discussão, no litoral da Bahia. Em Minas Gerais, datação U-Pb feita em um sill de metadiabásio na Serra do Espinhaço meridional resultou em $906 \mathrm{Ma}$ (Machado et al. 1989). Supõe-se que esse magmatismo fissural básico de caráter anorogênico, seja aproximadamente síncrono com a abertura do rift neoproterozóico (Teixeira 1993; Trompette 1994).

Os rifts Santo Onofre e Macaúbas e a bacia oceânica Araçuaí ( 900 - 750 Ma) O rifting gerado em decorrência da fase extensional no início do ciclo Brasiliano, provavelmente relaciona-se a uma junção tríplice (Burke 1980, Burke \& Dewey 1973), cujo braço NS (menos ativo?) penetra no sítio da Serra do Espinhaço setentrional, possivelmente por reativação da falha de Santo Onofre. Nesse rift setentrional depositou-se o Grupo Santo Onofre (redefinido). Os dois ramos meridionais formam o rift assimétrico Macaúbas que a leste passa, em uma etapa posterior, à uma margem continental passiva: a bacia oceânica Araçuaí. Esse modelo é mostrado, de forma esquemática, na parte inferior direita da figura 1 .

Com extensão superior a $500 \mathrm{~km}$, o rift Santo Onofre prossegue em sentido norte provavelmente ao longo das serras do Boqueirão e Estreito. Uma interpretação possível é de que o rift Santo Onofre una-se, à bacia ( faixa) Rio Preto, através de uma segunda junção tríplice.

O rift Santo Onofre inicia, na fase sinrift, por sedimentação continental que para cima, na fase pós-rift, passa para ambiente litorâneo e marinho profundo e calmo, associado a leques turbidíticos. Sua espessura é provavelmente de alguns milhares de metros. Na Chapada Diamantina, Dominguez \& Rocha (1991) e Dominguez (1993) referem-se a uma superfície erosiva na base da Formação Morro do Chapéu, contendo psamitos com conglomerados continentais, precedendo os diamictitos da Formação Bebedouro (Montes et al 1981).

A discordância observável no contato Caboclo/Morro do Chapéu constitui, segundo Dominguez \& Rocha (1991), um limite de seqüencia do tipo 7, dentro do conceito de ChristieBlick et al. (1988) e Van Wagoner et al. (1990). Na geração desse tipo de limite ocorre a formação de uma discordância com exposição subaérea na porção proximal da bacia e deposição de produtos dessa erosão nas partes distais. Durante períodos de mar baixo associados à formação de limites de seqüência do tipo $l$ são gerados lobos turbidíticos depositados por correntes de turbidez de alta densidade (Van Wagoner et iz/,1990, Dominguez 1993).

Dominguez \& Rocha (1991) destacam a importância do registro desse limite, pois representa uma quebra fundamental na sedimentação. Esse limite representa assim uma superfície de significado cronoestratigráfico. Essa descontinuidade na base da Formação Morro do Chapéu é uma acumulação típica de preenchimento de vales. É marcada por um conglomerado, localmente diamantífero, com seixos e matacões de até 30 centímetros de diâmetro, constituídos de calcário oolítico, estromatólitos, quartzitos e arenitos. A exposição da plataforma Caboclo em condições subaéreas levou à incisão de uma rede de drenagem, em seguida afogada por uma subseqüente ascensão do nível relativo do mar (Silveira 1991, Zanini et al. 1989). Da mesma forma, no extremo norte da Chapada Diamantina, Monteiro et al. (1984) descrevem semelhante descontinuidade na base da Formação Morro do Chapéu.

O grau de importância da quebra na sedimentação observada no contato Caboclo/Morro do Chapéu, ainda, não pode ser totalmente avaliado regionalmente. No entanto, é provável que essa quebra represente um hiato significativo na evolução geológica da região. Uma unidade de importância semelhante e talvez correlacionável à Formação Morro do Chapéu ocorre no extremo NW da Chapada Diamantina (Schobbenhaus 1972a, Costa et al 1975), a sudeste de Barra (Figura 1). Nessa região aflora uma unidade psamítica denominada informalmente de unidade Serra da Tabatinga (Schobbenhaus 1993), que cobre em discordância erosiva unidades progressivamente mais antigas, até a base do Grupo Paraguaçu, já sobre o embasamento arqueano, nos aluviões do Rio Paramirim. A discordância erosiva observada sugere que antes da deposição dos psamitos dessa unidade, mais de 4000 metros de sedimentos do Supergrupo Espinhaço podem ter sido erodidos nessa porção da Chapada Diamantina. Inda \& Barbosa (1978) correlacionaram a unidade Serra da Tabatinga à Formação Tombador e descrevem sua passagem para filitos da Formação Sítio Novo. A Formação Sítio Novo foi incluída por Inda \& Barbosa (1978) no Grupo Espinhaço Superior, na Serra do Espinhaço setentrional. A Formação Sítio Novo está amplamente distribuída ao longo do Rio Santo Onofre e encontra-se incluída no Grupo Santo Onofre redefinido. A discordância erosiva existente entre as formações Caboclo e Morro do Chapéu é uma forte evidência de que essa última represente a unidade Serra da Tabatinga. A correlação da unidade Serra da Tabatinga com o Grupo Santo Onofre redefinido permite concluir que a Formação Morro do Chapéu pode representar uma unidade neoproterozóica plataformal que a oeste, nos vales dos rios Paramirim e Santo Onofre, foi depositada sobre o Supergrupo Espinhaço ou sobre o embasamento do mesmo. Lobos turbidíticos descritos por Costa \& Silva (1980) e Dominguez \& Rocha (1989) no Grupo Santo Onofre redefinido reforçam o argumento de que os mesmos se assentam sobre a conformidade correlativa (Mitchum et al 1977) que constitui o prolongamento da discordância Caboclo/Morro do Chapéu. É possível, portanto, que os turbiditos do Grupo Santo Onofre sejam correlatives da Formação Morro do Chapéu (Dominguez 1996).

O rift Macaúbas, por sua vez, representa a continuação meridional do rift Santo Onofre, onde foram depositadas as fácies mais proximais do Grupo Macaúbas.O ambiente deposicional mostra transição de oeste para leste de ambiente glácio-costeiro a glácio-marinho proximal até ambientes marinhos distais com associação de vulcanismo de fundo oceânico de assinatura MORB, datado em torno de $800 \mathrm{Ma}$ (Sm-Nd) (Karfunkel \& Hoppe 1988, Pedrosa-Soares et al 1992, Pedrosa-Soares 1995). Nas fácies mais proximais do Grupo Macaúbas, situadas à oeste, a discordância erosiva acima relatada pode estar representada pelas formações Duas Barras (psamítica) e Peixe Bravo (psamo-pelítica), ambas pré-glaciais e situadas na base do Grupo Macaúbas (Noce et al 1993, Pedrosa-Soares 1996). Os quartzitos imaturos e mal selecionados de origem fluvial da Formação Duas Barras recobrem a Formação Domingas, a SW de Senador Mourão (Noce et al 1993). Essa última contém dolomites estroma- 
tolíticos com idade atribuída por Schöll (1976), entre 1350950 Ma. Uma correlação da Formação Domingas com a Formação Caboclo e da Formação Duas Barras com a Formação Morro do Chapéu é fortemente sugestiva.

A orogênese Brasiliana ( $\sim 650$ Ma) $O$ fechamento da bacia oceânica Araçuaí iniciou em cerca de $750 \mathrm{Ma}$ com fase precoce de deformação e metamorfísmo. Em torno de 650 Ma ocorreu o auge do período orogenético, acarretando deformação e metamorfísmo mais acentuados, acompanhados de intrusão de granitóides típicos de zonas de colisão continental, resultantes da fusão de crosta espessada (Siga Jr. 1986, Uhlein 1991, Pedrosa-Soares et al. 1992).

Ao longo do corredor de deformação do Paramirim, a deformação brasiliana afetou tanto o Grupo Oliveira dos Brejinhos, quanto o Grupo Santo Onofre redefinido, e foi gerada por um único esforço compressional (Costa \& Silva 1980, Uhlein \& Pedreira 1989, Bertholdo et al. 1993). Na região de Oliveira dos Brejinhos desenvolveu-se deformação

\section{FASE RIFT ESPINHACO (1750 Ma)}

DEPOSICĀO DAS FS. TOMBADOR E CABOCLO ( 1200-1000 Ma)

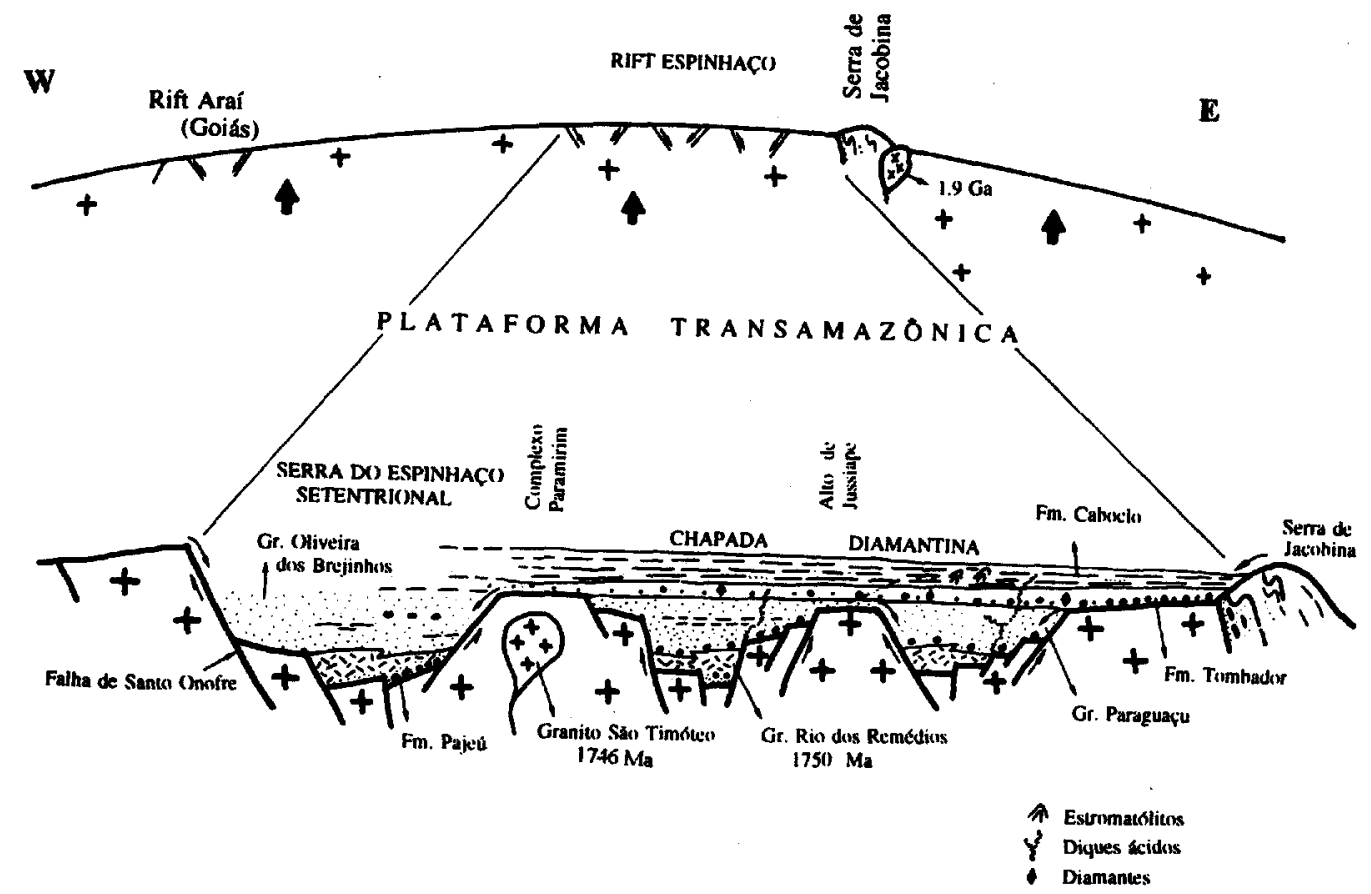

FASE RIFT SANTO ONOFRE ( $900 \mathrm{Ma}) \quad$ Paleo-relewo Jacobina-

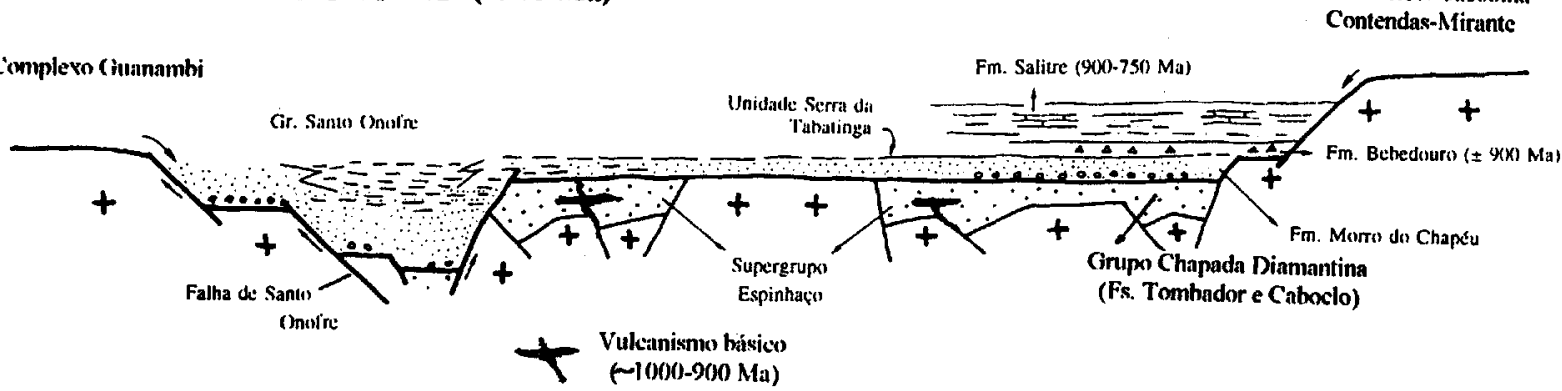

EVENTO TECTONO-METAMÓRFICO BRASILIANO ( $650 \mathrm{Ma})$

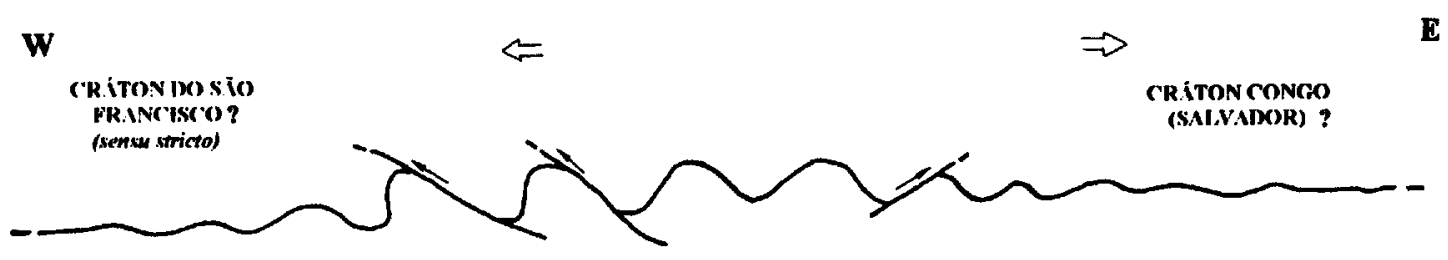

Figura 4 - Modelo evolutivo esquemático dos rifts Espinhaço e Santo Onofre, Bahia. Modificado de Schobbenhaus (1993). Figura 4 - Schematic evolution model of the Espinhaço and Santo Onofre rifts, Bahia. Modified from Schobbenhaus (1993). 
simples com dobras abertas que, no sentido sul, progridem em um estilo de deformação mais complexo, com dobras do tipo apertado a isoclinal e plano axial mergulhando forte para leste (Figuras 2 e 3). Esse dobramento por cisalhamento domina na parte sul do Grupo Santo Onofre (Costa \& Silva 1980, Jardim de Sá 1978, Uhlein \& Pedreira 1989). Os dois grupos sofreram metamorfísmo da fácies xisto verde até o início da fácies anfibolito, em condições de pressões intermediárias (barroviano) (Jardim de Sá 1978).

Na região de Caetité-Licínio de Almeida, rochas do complexo Paramirim, situadas à leste, foram empurradas sobre as unidades Santo Onofre e Espinhaço, deformando-as complexamente e induzindo-lhes metamorfismo inverso (cianitaestaurolita-granada-biotita-clorita), associado a zonas de cisalhamento dúctil e imbricação de unidades por deformação tangencial (Uhlein \& Pedreira 1989). Caby'\& Arthaud (1987) consideram que o modelo metamórfico-estrutural dessa região é consistente com thrusting do tipo himalaiano e pode ser relacionado a uma colisão continental. A parte oeste da Chapada Diamantina apresenta estruturação constituída comumente de dobras moderadamente fechadas com orientação geral NNW. À leste e norte, as dobras são suaves e abertas com magnitude de deformação baixa a insignificante, com eixos orientados aproximadamente N-S (Inda \& Barbosa 1978; Danderfer 1990, Monteiro et al. 1984). O grau de metamorfísmo acompanha essas deformações, passando de epimetamórfíco, à oeste, até metamorfísmo incipiente, à leste e à norte.

A Chapada Diamantina foi afetada por dois eventos deformacionais que afetam também a Formação Salitre, neoproterozóica, como pode ser observado no sinclinal de Irecê (Lagoeiro 1990, Montes et al. 1981). Um evento mais antigo, responsável pela estruturação geral da Chapada Diamantina com eixos NS a NW-SE, e um evento mais novo, considerado como reflexo, na zona cratônica, do desenvolvimento do cinturão brasiliano, na borda norte do cráton (faixa Rio Preto). Esses eventos deformacionais ocorreram no ciclo Brasiliano (Lagoeiro 1990; Danderfer 1990), ao que tudo indica de forma alocrônica: o fechamento da bacia Araçuaí/corredor do Paramirim antecedeu ao da bacia (faixa) Rio Preto.

Para explicar a inversão dos rifts superpostos no corredor do Paramirim, como já referido, Alkmim et al. (1993) admitem como hipótese mais provável a indução a partir de esforços de deformação das faixas Araçuaí e Rio Preto, uma vez que, segundo esses autores, faltam evidências da colisão de dois blocos continentais.
CONCLUSÕES 1. A existência de duas tafrogêneses superpostas na Serra do Espinhaço setentrional, Bahia, é proposta: o rift paleoproterozóico Espinhaço ( 1750 Ma), já reconhecido anteriormente, e o rift neoproterozóico Santo Onofre ( $900 \mathrm{Ma})$. De longa história geológica, a falha de Santo Onofre de direção meridiana e com mais de $500 \mathrm{~km}$ de extensão, mui provavelmente exerceu papel essencial na instalação dessas estruturas (Figura 1).

2. No rift Santo Onofre, alguns milhares de metros de sedimentos foram depositados em ambientes que variam de continental, marinho raso a marinho profundo de águas calmas, este último associado a leques turbidíticos. Esse pacote sedimentar é redefinido como Grupo Santo Onofre e corresponde, em trabalhos anteriores, às formações Santo Onofre e Sítio Novo, unidades de topo do Supergrupo Espinhaço (Figuras 2 e 3 ).

3. Na Serra do Espinhaço central, norte de Minas Gerais, as fácies pelito-psamíticas do Grupo Santo Onofre têm continuidade no Grupo Macaúbas. A origem dessas unidades é sugerida a partir de uma junção tríplice, gerada em decorrência de uma fase extensional entre 1000 e $900 \mathrm{Ma}$. O ramo setentrional dessa junção, menos ativo, corresponde ao rift Santo Onofre. Os dois ramos meridionais geraram o rift/bacia oceânica Macaúbas/Araçuaí. Uma ligação do rift Santo Onofre com o rift (bacia) Rio Preto, a norte, é também admitida (sistema Araçuaí-Paramirim-Rio Preto) (Figuras le 4).

4. Com o fechamento do rift durante a orogênese Brasiliana, a deformação que gerou a faixa dobrada Araçuaí, também atuou ao longo do corredor do Paramirim deformando o Grupo Santo Onofre, o Supergrupo Espinhaço e o seu embasamento.

5. As formações Morro do Chapéu, Caboclo e Tombador representam unidades sem relação com o Supergrupo Espinhaço. Entre essas formações e o Supergrupo Espinhaço deve existir um hiato de pelo menos 500 Ma. A Formação Morro do Chapéu é interpretada como geneticamente relacionada ao Grupo Santo Onofre redefinido, sendo portanto ambas de idade neoproterozóica. As formações Tombador e Caboclo são depósitos plataformais, relacionados provavelmente à um evento de idade grenvilliana, em torno de 1200-1000 Ma (Figuras 1 e 4).

Agradecimentos O autor expressa agradecimentos aos colegas Antônio Carlos Pedrosa-Soares, Benjamim Bley de Brito Neves e Ivo A. Dussin pelas valiosas críticas e sugestões que em muito contribuíram para o aprimoramento deste trabalho.

\section{REFERÊNCIAS}

ALKMIM, F. F.; BRITO NEVES, B.B. \& CASTRO ALVES, J.A. 1993. Arcabouço tectônico do Cráton do São Francisco -uma revisão. In Dominguez, J.L.M \& Misi, A. eds.- O Cráton do São Francisco. Salvador. SBG/SGM/CNPq. p. 45-63.

ALMEIDA, F.F.M. de. 1977.0 Cráton do São Francisco. Revista Brasileira de Geociências, 7(4):349-364.

ALMEIDA, F.F.M. DE; HASUI, Y.; RODRIGUES, E. de P. \& YAMAMOTO, J.K. 1978. A faixa de dobramentos Araçuaí na região de Rio Pardo. In: CONGRESSO BRASILEIRO DE GEOLOGIA, 30. Recife, 1978. Anais... Recife, SBG, p. 270-283.

ALMEIDA-ABREU, P.A. 1995. O Supergrupo Espinhaço na Serra do Espinhaço Meridional (Minas Gerais): O rifte, a bacia e o orógeno. Geonomos 3 (1): 1 -18.

ALMEIDA-ABREU, P.A. \& PFLUG, R. 1994. Geodynamic evolution of the Southern Serra do Espinhaço, Minas Gerais, Brazil. Zeitblait für Geologic und Palaonlologie, HI/2:21-44.

BABINSKI, M.; VAN SCHMUS, W.R.; CHEMALE, F.; BRITO NEVES, B.B. de \& ROCHA, A.J.D. 1993. Idade isocrônica $\mathrm{Pb} / \mathrm{Pb}$ em rochas carbonáticas da Formação Caboclo, em Morro do Chapéu, BA. In: SIMPÓSIO SOBRE O CRÁTON DO SÃO FRANCISCO, 2, Salvador, 1993. Anais... Salvador, SBG/SGM BA/CNPq. p. 160-163.
BABINSKI, M.; BRITO NEVES, B.B. de; MACHADO, N.; NOCE, C.M.; UHLEIN, A. \& VAN SCHMUS, W.R. 1994. Problemas da metodologia $\mathrm{U} / \mathrm{Pb}$ em zircões de vulcânicas continentais: caso do Grupo Rio dos Remédios, Supergrupo Espinhaço, no estado da Bahia. In: CONGRESSO BRASILEIRO DE GEOLOGIA, 38, Balneário Camboriú, 1994. Anais... Balneário Camboriú, SBG-DNPM-CPRM. V. 2, p. 409-410.

BATES, R. L. \& JACKSON, J.A. 1987. Glossary of Geology. 3 ed. Virginia, American Geological Institute. 788 p.

BERTHOLDO, A.L.; ALKMIM, F.F. \& TROUW, R.A. 1993. O comportamento estrutural das coberturas meso e neoproterozóicas do cráton do São Francisco nas Serra do Espinhaço setentrional, Central e Palmas do Monte Alto (MG-BA). In: SIMPÓSIO SOBRE O CRÁTON DO SÃO FRANCISCO, 2, Salvador, 1993. Anais... Salvador, SBG. p. 205-207.

BOMFIM, L.F.C. \& PEDREIRA, A.J. eds. 1990. Lençóis (folha SD.24-V-A-V), 1:100.000. In: DNPM-CPRM. Programa Levantamentos Geológicos Básicos do Brasil, Brasília, 145p.

BRANNER, J.C. 1910. The Tombador Escarpment in the State of Bahia, Brazil. American Journal of Sciences, 4 series, 35:619-632.

BRITO NEVES, B.B. de. 1967. Geologia das Folhas de Upamirim e Morro do Chapéu, Bahia. SUDENE/CONESP, Relatório 17, 53 p. (inédito). 
BRITO NEVES, B.B. de; KAWASHITA, K. \& DELHAL, J. 1979. A evolução geocronológica da Cordilheira do Espinhaço: dados novos e integração. Revista Brasileira de Geociências, 9(1):71-85.

BRITO NEVES, B.B. de; CORDANI, U.G. \& TORQUATO, J.R.F. 1980. Evolução geocronológica do precambriano do Estado da Bahia In: H.A.V. Inda \& F.B. Duarte eds., Geologia e Recursos Minerais do Estado da Bahia, Salvador,. CPM-SME BA, v.3, p. 1 -101. (Textos Básicos).

BRITO NEVES, B.B. de; VAN SCHMUS, W.R.; SANTOS, E. J. dos; CAMPOS NETO, M.C. \& KOZUCH, M. 1996. O evento Carirís Velhos na Província Borborema: integração de dados, perspectivas e implicações. In: CONGRESSO BRASILEIRO DE GEOLOGIA, 34, Salvador, 1986. Anais... Salvador, SBG. vol. 6, p.19-22.

BURKE, K.C. \& DEWEY, J.F. 1973. Plume generated triple junctions: Key indicators in applying plate tectonics to old rocks. Journal of Geology, 81:406-433

BURKE, K. 1980. Intracontinental rifts and aulacogens. In: National Research Council ed., Continental Tectonics, Washington., NAS, p. 42-49.

CABY, R.R., ARTHAUD, M. 1987. Petrostructural evolution of the Lagoa Real subalcaline metaplutonic complex (Bahia, Brazil). Revista Brasileira de Geociências, 17(4):636-636.

CHRISTIE-BLICK, N.; GROTZINGER, J.P. \& VON DER BORCH, C.C. 1988. Sequence stratigraphy in Proterozoic successions. Geology, $p$. 100-104.

CONCEIÇÃO, T.M.L. 1974. Petrologia e geoquímica de rochas efusivas de Ibitiara-Bahia. Salvador. 61 p. (Dissertação de Mestrado, Instituto de Geociências da Universidade Federal da Bahia).

CORDANI, U.G. 1973. Evolução geológicapré-cambriana dafaixa costeira do Brasil entre Salvador e Vitória. São Paulo. 98 p. (Dissertação de Livre Docência, Instituto de Geociências da Universidade de São Paulo).

CORDANI, U.G.; IYER, S.S.; TAYLOR, P.N.; KAWASHITA, K.; SATO, K. \& MCREATH, I. 1992. Pb-Pb, Rb-Sr, and K-Ar systematics of the Lagoa Real uranium province (south-central Bahia, Brazil) and the Espinhaço Cycle (ca. 1.5-1.0 Ga). Journal of South American Earth Sciences, 5(1):33-46

COSTA, L.A.M. da \& INDA, H.A.V. 1982. O aulacógeno do Espinhaço. Ciências da Terra, 2:13-18.

COSTA, L.A.M. da \& SILVA, W.G. da. 1980. Projeto Santo Onofre-Mapeamento Geológico; Relatório Final. DNPM-CPRMTRISERVICE (inédito).

COSTA, L.A.M. da; BAPTISTA, M.B.; SILVA, W.G. da; PORTELA, A.C.P.; MOSSMAN, R.; STEIN, J.H. \& MARCHETTO, C.M.L. 1975 Projeto Leste do Tocantins/Oeste do São Francisco-Geologia estratigráfica, estrutural e econômica. DNPM-CPRM-PROSPEC (inédito).

DANDERFER FILHO, A. 1990. Análise estrutural descritiva e cinemática do Supergrupo Espinhaço na região da Chapada Diamantina (BA). Ouro Preto. 119 p. (Dissertação de Mestrado, Instituto de Geociências da Universidade Federal de Ouro Preto).

DERBY, O. A. 1906. The Serra do Espinhaço, Brazil. Journal of Geology, 14:374-401.

DOMINGUEZ, J.M.L. 1993. As coberturas do Cráton do São Francisco: uma abordagem do ponto de vista da análise de bacias. In: DOMINGUEZ, J.M.L. \& MISI, A. eds. O Cráton do São Francisco. Salvador, SBG. p. $137-159$

DOMINGUEZ, J.M.L. 1996. As coberturas plataformais do Proterozóico Médio e Superior. In: J.F.S. BARBOSA \& J.M.L. DOMINGUEZ eds. Geologia da Bahia. Salvador, SGRM-UFBa-FAPEX. p. 103-125.

DOMINGUEZ, J.M.L.; ROCHA, G.M.F. \& FUCK, R.A. 1996. Proterozóico Superior e Proterozóico Médio. In: J.F.S. BARBOSA \& J.M.L.

DOMINGUEZ eds. Geologia da Bahia. Salvador, SGRM-UFBa-FAPEX. p.273-301.

DOMINGUEZ, J.M.L. \& ROCHA, G.M.F. 1989. Seqüências deposicionais do Espinhaço Setentrional na região sudoeste do Estado da Bahia. Uma margem continental Proterozóica? In: SIMPÓSIO DE GEOLOGIA DE MINAS GERAIS, 1./SIMPÓSIO DE GEOLOGIA DE BRASÍLIA, 5. Belo Horizonte, 1989. Anais... Belo Horizonte, SBG. p. 190-194.

DOMINGUEZ, J.M.L. \& ROCHA, A.J.D. 1991. Grupos Chapada Diamantina (Proterozóico Médio) e Una (Proterozóico Superior). In: CONFERÊNCIA DE CAMPO "O PROTEROZÓICO MÉDIO E SUPERIOR NO BRASIL", Morro do Chapéu, 1991. SBG. 27 p.

DUSSIN, I.A. \& DUSSIN, E.M. 1995. Supergrupo Espinhaço: Modelo de evolução geodinâmica. Geonomos 3(1): 19-26.

DUSSIN, T.M.; DUSSIN, I.A.; ROSSI, P. \& ÇHARVET, J. 1995. Idade do Supergrupo Espinhaço: determinação ${ }^{207} \mathrm{~Pb} /{ }^{206} \mathrm{~Pb}$ pelo método de evaporação do $\mathrm{Pb}$ sobre monozircões de metavulcanitos sinsedimentares. SIMPÓSIO DE GEOLOGIA DE MINAS GERAIS, 8. Anais... Belo Horizonte, SBG. Bol. 13, p. 11-13.
FERNANDES, P.E.C.A.; MONTES, M.L.; BRAZ, E.R.C.; MONTES, A. de S.L.; SILVA, L.L.; OLIVEIRA, F.L.L.; GHIGNONE, J.I. SIGA Jr., O. \& CASTRO, H.E.F. 1982. Geologia, Folha SD. 24-Brasília. In: Projeto Radambrasil-Levantamento de Recursos Naturais, Rio de Janeiro.

FUCK, R.A. 1991. Aprovada nova escala de tempo para o Pré-Cambriano. Revista Brasileira de Geociências, 21(2): 182-183.

GOODWIN, A.M. 1991. Precambrian Geology-The dynamic evolution of the continental crust. Academic Press, $666 \mathrm{p}$.

GUIMARÃES, J.T. \& PEDREIRA, A.J. ed. 1990. Utinga (folha SD.24-V-A-II), 1:100.000. In: Programa Levantamentos Geológicos Básicos do Brasil, Brasília, DNPM-CPRM, 154 p.

HOFFMAN, P.P. 1973. Evolution of an Early Proterozoic continental margin: the Coronation geosyncline and associated aulacogens of the northwestern Canadian Shield. Philosophical Transactions of the Royal Society of London, A273:547-581.

HOPPE, A. 1988. Arenitas cuarciferas del Proterozóico temprano. In: Actas de la Facultadde Ciências de la Tierra, Universidad Autônoma Nuevo Leon, 3, Linares/Mexico.

INDA, H.A.V. \& BARBOSA, J.F. 1978. Texto explicativo para o Mapa Geológico do Estado da Bahia, Escala 1:1.000.000. Salvador, CPM-SME BA/CBPM, 137p.

JARDIM DE SÁ, E.F. 1978. Geologia da Chapada Diamantina e Faixa Santo Onofre, Bahia, e geoquímica do vulcanisno ácido associado. Salvador, 180 p. (Dissertação de Mestrado, Instituto de Geociências da Universidade Federal da Bahia).

JARDIM DE SÁ, E.F. 1981. A Chapada Diamantina e a faixa Santo Onofre: um exemplo de tectônica intraplaca no Proterozóico Médio do Cráton do São Francisco. In: INDA; H.A.V.; MARINHO, M.M. \& DUARTE, F.R. eds. Geologia e Recursos Minerais do Estado da Bahia, CPM BA. v.4, p. 111-120 (Textos Básicos).

KARFUNKEL, J. \& HOPPE, A. 1988. Late Proterozoic glaciation in Central Eastern Brazil: synthesis and model. Paleogeography, Paleoclimatology, Paleoecology, 65:1-21.

KAUL, P.F.T. 1970. Geologia da Quadricula de Boquira. SUDENE, Recife. 75 p. (inédito).

LAGOEIRO, L.E. 1990. Estudo da deformação nas seqüencias carbonáticas do Grupo Una, na região de Irecê, Bahia. Ouro Preto. 105 p. (Tese de Mestrado, Universidade Federal de Ouro Preto).

LEAL, A. de S. \& BRITO NEVES, B.B. de. 1968. Elementos daestratigrafia do médio São Francisco. In: SIMPÓSIO DE GEOLOGIA DO NORDESTE, 4, Recife, 1968. Resumo das Comunicações... Recife, SBG. p. $17-19$

MACEDO, M.H. DE F. \& BONHOMME, M.G. 1984. Contribuição à cronoestratigrafia das Formações Caboclo, Bebedouro e Salitre na Chapada Diamantina (BA), pelos métodos $\mathrm{Rb}-\mathrm{Sr}$ e K-Ar. Revista Brasileira de Geociências, 14(3): 153-163.

MACHADO, N.; SCHRANK, A.; ABREU, F.R.; KNAUER, L.G. \& ALMEIDA-ABREU, P.A. 1989. Resultados preliminares da geocronologia $\mathrm{U} / \mathrm{Pb}$ na Serra do Espinhaço Meridional. In: SIMPÓSIO DE GEOLOGIA DO NÚCLEO MINAS GERAIS, 5, $J$ SIMPÓSIO DE GEOLOGIA DO NÚCLEO DE BRASÍLIA, 1. Anais... SBG, Bol. 10:171-174

MASCARENHAS, J.F. de; PEDREIRA, A.J. de C.L.; GIL, C.A.A.; NEVES, J.P. das; OLIVEIRA, J.E. de; SILVA FILHO, M.M. da \& MARINHO, M.M. 1979. Geologia da região centro-oriental da Bahia - Projetos Bahia II-Sul da Bahia, Relatório Integrado. DNPM-CPRM, 128 p., Brasília (inédito).

MCREATH, I.; JARDIM DE SÁ, E.F. \& FRYER, B.J. 1981. As vulcânicas ácidas proterozóicas da região da bacia do Rio Paramirim-BA. In: INDA, H.A.V. \& DUARTE, F.B. eds. Geologia e Recursos Minerais do Estado da Bahia. CPM BA, v. 4, p. 121-134. (Textos Básicos).

MITCHUM, R.M.; VAIL, P.R. \& THOMPSON, S. 1977. Seismic stratigraphy and global changes of sea level, Part 2: The depositional sequence as a basic unit for stratigraphic analysis. In: C.E. PAYTON ed. Seismic Stratigraphy-Applications to Hydrocarbon Exploration. Memoir of the American Association of Petroleum Geologists, 26:53-62.

MONTEIRO, M.D.; CARVALHO, M.P. de \& CONCEIÇÃO FILHO, V.M. 1984. Caracterização faciológica e sistemas deposicionais do Grupo Chapada Diamantina.-In: CONGRESSO BRASILEIRO DE GEOLOGIA, 33, Rio de Janeiro. Anais... Rio de Janeiro, v. 3, p. $1090-1105$.

MONTES, A. de S.L.; MONTES, M.L. \& DARDENNE, M.A. 1981. A região da Serra de Jacobina, um paleorelevo ativo durante a sedimentação dos Grupos Chapada Diamantina e Bambuí. In: SIMPÓSIO SOBRE O CRÁTON DO SÃO FRANCISCO E SUAS FAIXAS MARGINAIS, Salvador, 1981. Anais... SBG, Salvador. p.79-86.

MONTES, M.L. 1977. Os conglomerados diamantíferos da Chapada Diamantina-Bahia, Brasil. Brasília. (Tese de Mestrado, Instituto de Geociências da Universidade de Brasília). 
NOCE, C.M ; GROSSI SAD, J.H.; PEDROSA-SOARES, A.C.; GUIMARÃES, M.L.V.; MOURÃO, M.A.A.; OLIVEIRA, M.J.R. \& ROQUE, N.C. 1993. Litoestratigrafia do Grupo Macaúbas na Faixa Aracuaí, Minas Gerais. IGC-UFMG. 18 p. (inédito).

OTERO, E.P.; DOMINGUEZ, J.M.L. \& UMA, C.C.U. de. 1989. Sedimentação flúvio-eólica no Proterozóico Médio, Formação Tombador, Grupo Chapada Diamantina, Estado da Bahia. SIMPÓSIO DE GEOLOGIA DO NÚCLEO MINAS GERAIS, 5, SIMPÓSIO DE GEOLOGIA DO NÚCLEO DE BRASÍLIA, 1, Belo Horizonte, 1989. Anais... Belo Horizonte, SBG. p. 212-217.

PEDREIRA, A. J. \& M ARC ALHO, R.de S.F.X.M. eds. 1990. Mucugê (folha SD.24-V-C-II), 1:100.000. In: Programa Levantamentos Geológicos Básicos do Brasil, Brasilia, DNPM/CPRM. 122 p.

PEDREIRA, A.J. 1988. Seqüências deposicionais no Precambriano: exemplo da Chapada Diamantina Oriental, Bahia. In: CONGRESSO BRASILEIRO DE GEOLOGIA, 35, Belém, 1988. Anais... Belém, SBG. v.2, p.648-659.

PEDROSA-SOARES, A.C.; NOCE, C.M.; VIDAL, P.H.; MONTEIRO, R.L.B.P. \& LEONARDOS, O.H. 1992. Toward a new tectonic model for the Late Proterozoic Araçuaí (SE Brazil) - West Congolian (SW Africa) Belt. Journal of South American Earth Sciences, 6(1/2):33-47.

PEDROSA-SOARES, A.C. 1995. Potencial aurifero do vale do Aracuai MG: história da exploração, geologia e controle tectono-metamórfico. Brasília, 177 p. (Tese de Doutorado, Instituto de Geociências da Universidade de Brasília).

PEDROSA-SOARES, A.C. 1996. O setor setentrional da Faixa Araçuaí. In CONGRESSO BRASILEIRO DE GEOLOGIA, 39, Salvador, 1996 Excursões... Salvador, SBG. Excursão E-12, p. 13-49.

PFLUG, R.; SCHOBBENHAUS, C. \& RENGER, F. 1969. Contribuição à geotectônica do Brasil Oriental, Recife, SUDENE, 57 p. (Série Especial 9).

PIMENTEL, M.M.; HEAMAN, L.; FUCK, R.A. \& MARINI, J.O. 1991. $\mathrm{U}-\mathrm{Pb}$ zircon geochronology of Precambrian tin-bearing continental-type acid magmatism in central Brazil. Precambrian Research, 52:321-335.

PIMENTEL, M.M.; MACHADO, N. \& LOBATO, L.M. 1993. Geocronologia U-Pb de rochas graníticas e gnáissicas da região de Lagoa Real, Bahia, e implicações para a idade da mineralização de urânio. In: CONGRESSO BRASILEIRO DE GEOLOGIA,38, Balneário Camboriú, 1993.Anais... Balneário Camboriú, SBG. vol. 2, p.389-390.

PORCHER, C.A. 1970. Geologia das Quadrículas fpupiara e Oliveira dos Brejinhos, Bahia, Recife, SUDENE, 62 p. (Relatório Interno).

ROCHA, A.J.D.; PEREIRA, C.da P. \& SRIVASTAVA, N.K. 1990. Seqüências carbonáticas da Formação Caboclo na folha Morro do Chapéu (Bahia). In: CONGRESSO BRASILEIRO DE GEOLOGIA, 36, Natal, 1990. Anais... SBG, Natal. v. 2, p. 49-65.

ROCHA, G.M.F. \& DOMINGUEZ, J.M.L. 1993. As fases de deformação atuantes nos supergrupos Espinhaço e São Francisco no Estado da Bahia. In: SIMPÓSIO SOBRE O CRÁTON DO SÃO FRANCISCO E SUAS FAIXAS MARGINAIS, 2, Salvador, 1993. Anais.. SBG-SGM BA, Salvador, p. 200-204.

SCHOBBENHAUS, C. 1972a. Relatório geral sobre a geologia da região setentrional da Serra do Espinhaço-Bahia central. SUDENE, Recife, 112 p. (Série Geologia Regional 19).

SCHOBBENHAUS, C. 1972b. Geologia da Serra do Espinhaço entre Porteirinha e Monte Azul, norte de Minas Gerais. SUDENE, Recife, 19 p. (inédito)

SCHOBBENHAUS, C. 1972c. Estudo geoeconômico preliminar do depósito de ferro do Rio Peixe Bravo, norte de Minas Gerais. SUDENE, Recife, 36 p. (Série Geologia Econômica 8).

SCHOBBENHAUS, C. \& KAUL, P.F.T. 1971. Contribuição à estratigrafia da Chapada Diamantina, Bahia Central. Mineração e Metalurgia, 53(315):116-120.

SCHOBBENHAUS, C.; CAMPOS, D. de A.; DERZE, G.R. \& ASMUS, H.E 1981. Mapa Geológico do Brasil e da Área Oceânica Adjacente Incluindo Depósitos Minerais, Escala $1: 2.500 .000$, DNPM, Brasília.

SCHOBBENHAUS, C. 1993. O Proterozóico Médio no Brasil com ênfase à Região Centro-Leste. Freiburg im Breisgau, 166 p. (Tese de Doutorado, Geowissenschaftliche Fakultät, Albert-Ludwigs-Universitàt Freiburg im Breisgau).

SCHOBBENHAUS, C.; HOPPE, A.; BAUMANN, A. \& LORCK, A. 1994 Idade $\mathrm{U} / \mathrm{Pb}$ do vulcanismo Rio dos Remédios, Chapada Diamantina, Bahia. In: CONGRESSO BRASILEIRO DE GEOLOGIA, 38, Balneário Camboriú, 1994. Anais... Balneário Camboriú, SBG-DNPM-CPRM. v. 2, p. 397-399.

SCHÖLL, W. 1976. Estromatólitos (Conophyton) em dolomites do Grupo Macaúbas. In: CONGRESSO BRASILEIRO DE GEOLOGIA, 29, Belo Horizonte, 1976. Anais... Ouro Preto, SBG. v.2, p.67-73.
SIGA Jr., O. 1986. A evolução geotectônica da porção nordeste de Minas Gerais, com base em interpretações geocronológicas. São Paulo, 140 p. (Tese de Mestrado, Instituto de Geociências.Universidade de São Paulo).

SILVA, M.E. da; KARMANN, I. \& TROMPETTE, R. 1989. Litoestratigrafia do Supergrupo Espinhaço e Grupo Bambuí no noroeste do Estado da Bahia. Revista Brasileira de Geociencias, 19(2):141-152.

SILVEIRA, J.S. 1991. Dinâmica de sedimentação de um mar raso antigo. formações Caboclo e Morro do Chapéu (Proterozóico Médio), Grupo Chapada Diamantina-Estado da Bahia. Salvador, 180 p. (Tese de Mestrado, Instituto de Geociências, Universidade Federal da Bahia).

SOUZA, W.S.T. de. 1986. Contribuição aos estudos de revisão estratigráfica do Pré-Cambriano Brasileiro a partir da utilizacão do conceito de unidade deposicional. In: CONGRESSO BRASILEIRO DE GEOLOGIA, 34, Goiânia. Anais... Goiânia, SBG. v. 1, p. 391-404.

TÁVORA, F.J.; CORDANI, U.G. \& KAWASHITA, K. 1967. Determinação de idade Potássio-Argônio em rochas da região central da Bahia. In CONGRESSO BRASILEIRO DE GEOLOGIA, 21, Curitiba. Anais.. Curitiba, SBG. p. 214-224.

TEIXEIRA, W. 1982. Geochronology of the southern part of the São Francisco Craton. Revista Brasileira de Geociências, 12 (1-3):268-277.

TEIXEIRA,W. 1993. Avaliação do acervo de dados geocronológicos e isotópicos do Cráton do São Francisco-implicações tectônicas. In DOMINGUEZ, J.M.L. \& MISI, A. eds. O Cráton do São Francisco, Salvador. SBG/SGM/CNPq. p. 11-33.

TROMPETTE, R. 1994. Geology of Western Gondwana (2000-500 Ma). Pan-African-Brasiliano Aggregation of South America and África. Amsterdam, Balkema. $350 \mathrm{p}$.

TROMPETTE, R. UHLEIN, A. SILVA, M.E da \& KARMANN, I. 1992. The Brasiliano São Francisco craton revisited (central Brazil). Journal of South American Earth Sciences, 6(1/2):49-57.

TURPIN, L..MARUEJOL, P. \& CUNEY, M. 1988. U-Pb, Rb-Sr and Sm-Nd chronology of basement, hydrotermal albitites and uranium mineralization (Lagoa Real, South Bahia, Brazil). Contributions to Mineralogy and Petrology, 98(2): 139-147.

UHLEIN, A. 1991. Transição cráton-faixa dobrada : exemplo do craton do São Francisco e dafaixa Araçuai (ciclo Brasiliano) no estado de Minas Gerais. Aspectos estratigráficos e estruturais. São Paulo,295 p. (Tese de Doutorado.Instituto de Geociências, Universidade de São Paulo).

UHLEIN, A.; TROMPETTE, R.R. \& SILVA, E. da M. 1986. Estruturação tectônica do Supergrupo Espinhaço na região de Diamantina (MG) Revista Brasileira de Geociências, 16(2):212-216.

UHLEIN, A. \& PEDREIRA, A.J. 1989. Consideracooes sobre a geologia estrutural, tectônica e fácies sedimentares do Espinhaço setentrional e Chapada Diamantina (BA\}. In: SIMPÓSIO DE GEOLOGIA DE MINAS GERAIS,5, SIMPOSIO DE GEOLOGIA DE BRASÍLIA,1, Belo Horizonte, 1989. Anais... Belo Horizonte, SBG. p.180-183.

UHLEIN, A.; SILVA, M.E. \& TROMPETTE, R.A. 1990. A Faixa de Dobramentos Araçuaí no Estado de Minas Gerais: uma cadeia monocíclica de idade brasiliana. In: CONGRESSO BRASILEIRO DE GEOLOGIA, 36, Natal, 1990. Anais... Natal, SBG. v. 6, p. 2576-2588.

VAN WAGONER, J.C.; MITCHUM, R.M.; CHAMPION, K.M. \& RAHMANIAN, V.D. 1990. Siliciclastic sequence stratigraphy in well logs, cores, and outcrops: concepts for high-resolution correlation of time and fades. American Association of Petroleum Geologists, Methods in Exploration Series 7, $55 \mathrm{p}$.

VIVEIROS, J.F.M.de; SÁ, E.L.; VILELA, O.V.; SANTOS, O. de M. \& MOREIRA, J.M.P. 1978. Geologia dos vales dos rios Peixe Bravo e Alto Vacaria, Norte de Minas Gerais. In: CONGRESSO BRASILEIRO DE GEOLOGIA, 30, Recife, 1978. Anais... Recife, SBG. v. 1, p. 243-254

WINDLEY, B.F. 1984. The evolving continents. 2ed. London, Wiley. 399 p.

WINGE, M. 1968. Geologia da região das serras do Estreito e do Boqueirão-NW da Bahia e SSE do Piauí. SUDENE, Recife, 80 p. (relatório inédito).

ZANINI Jr., A.; DOMINGUEZ; J.M.L. \& LEÃO, Z.M. de A.N. 1989. Estruturas de contração em planícies de marés terrígenas da Formação Morro do Chapéu-Grupo Chapada Diamantina (Proterozóico Médio/Bahia). In: SIMPÓSIO DE GEOLOGIA DE MINAS GERAIS, 5, SIMPOSIO DE GEOLOGIA DE BRASIILIA.l, Belo Horizonte, 1989. Anais... Belo Horizonte, SBG. p. 206-211.

Manuscrito A908

Recebido em 18 de fevereiro de 1997 Revisão do autor em I de junho de 1997 Revisão aceita em 4 de junho de 1997 